\title{
Argümantasyon Tabanlı Bilim Öğrenme Yaklaşımının Öğrencilerin Matematik Başarılarına Etkisi*
}

\section{Betül KÜÇÜK DEMİ***, Tevfik İSLEYEN***}

Öz: Bu araştırmanın amacı, Argümantasyon Tabanlı Bilim Öğrenme (ATBÖ) yaklaşımının ortaöğretim 9. sınıf öğrencilerinin fonksiyonlar konusundaki matematik başarısına olan etkisini araştırmaktır. Çalışma örneklemini 2012-2013 eğitim-öğretim yılında Bayburt'ta bir lisede 9. sınıfta öğrenim gören toplam 22 öğrenci oluşturmaktadır. Çalışmada nicel yöntem kullanılmıştır ve çalışma tek grup ön test-son test zayıf deneysel araştırma deseninden oluşmaktadır. Veri Toplama aracı olarak; araştırmacı tarafından geliştirilen "Fonksiyon Başarı Testi(FBT)” ve Matematik Muhakeme Yaklaşımı (MMY) öğrenci şablonu kullanılmıştır. Fonksiyon Başarı Testi için ön test-son testten elde edilen verilerin çözümlenmesinde SPSS 18.0 paket programı kullanılmıştır. Parametriğin şartları olan normallik şartı için çarpıklık (skewness) ve basıklık (kurtosis) değerlerine bakılmıştır ve bu değerler -1 ve +1 arasında olup Eşleştirilmiş örneklem t-testi yapılmıştır. Kategorilere ayrıştırılan Fonksiyon Başarı Testi'nin çarpıklık (skewness) ve basıklık (kurtosis) değerleri -1 ve +1 arasında olup Eşleştirilmiş örneklem t-testi kullanılmıştır. Öğrencilerin hazırladıkları MMY raporlarının değerlendirilmesi sonucunda elde edilen puanlar ile FBT son testinden aldıkları puanlar arasındaki korelasyona bakılmıştır. Araştırma sonucunda elde edilen bulgulara göre Argümantasyon Tabanlı Bilim Öğrenme yaklaşımı temel alınarak işlenilen fonksiyonlar konusu öncesinde ve sonrasında öğrencilere uygulanan başarı testi sonuçları değerlendirildiğinde son test lehine anlamlı bir

\footnotetext{
* Bu çalışma birinci yazarın doktora tezinin bir bölümünden oluşmaktadır.

**Dr. Öğr. Üyesi, Bayburt Üniversitesi, Eğitim Fakültesi, Matematik ve Fen Bilimleri Eğitimi Bölümü, Email: betulkucuk@bayburt.edu.tr Orcid No: 0000-0002-6752-6803.

${ }^{* * *}$ Doç.Dr. Atatürk Üniversitesi, Eğitim Fakültesi, Matematik ve Fen Bilimleri Eğitimi Bölümü, Email: tisleyen@atauni.edu.tr Orcid No: 0000-0001-9349-4078.
}

$\begin{array}{lll}\text { Gönderim: 02.04.2019 Kabul:18.06.2019 } \quad \text { Yayın: 15.09.2019 } & \text { Ka }\end{array}$


farklılığın olduğu tespit edilmiştir. MMY rapor puanlarıyla FBT son test puanları arasında olumlu, orta düzeyde ve anlamlı düzeyde bir ilişki tespit edilmiştir $(r=.614)$.

Anahtar Kelimeler: Argümantasyon, matematik, başarı, fonksiyon, 9.sınıf öğrenci

\section{The effect of the argumentation based science learning approach on the mathematics achievement of students}

Abstract: The aim of this research is to investigate the effect of the Argument Based Science Learning (ABSL) approach on 9th grade students of secondary school on mathematics achievement in terms of functions. The study sample consists of 22 students in Bayburt who study in the 9th grade in a high school during the 2012-2013 academic year. A quantitative method was used in the study and the study consisted of a single experimental group with pretest and post-test weak experimental design. As a data collection tool; "Functional Achievement Test (FAT)" developed by the researcher and Mathematics Reasoning Approach (MRA) student template are used as data collection tools. The SPSS 18.0 package program was used in the analysis of the data obtained from the pre-test post-test for the Functional Achievement Test. The skewness and kurtosis values for the normality condition, which is the condition of the parametric, were examined between -1 and +1 and the paired sample t-test was performed. The skewness and kurtosis values of the Functional Achievement Test, which are separated into categories, are between -1 and +1 and the paired sample t-test is used. The correlation between scores in MRA reports and scores in FAT post-test test was examined. According to the results obtained from the research, it was determined that there is a significant difference in favor of the end test when evaluating the achievement test results applied to the students before and after the functions based on the Argument Based Science Learning approach. A moderate, positive significant relation was found between MRA report scores and FST posttest scores $(\mathrm{r}=.614)$.

Keywords: Argumentation, mathematics, achievement, function, $9^{\text {th }}$ grade student

\section{Giriş}

Okullarda iyi bir matematik öğretiminin gerekliliği eğitimin her kademesinde önemli bir amaç olarak görülmektedir. Toplumun her kesiminde öğrencilerin matematikteki başarısının, diğer derslerde gösterdikleri başarıdan daha önemli ve belirleyici rol oynadığı kanısı yaygındır. $\mathrm{Bu}$ sebeple, matematik öğretiminin neden gerekli olduğunun herkes tarafindan iyice bilindiği varsayılabilir (Karaçay, 2000). Günümüzde bireylerden öğrendikleri yeni bilgiyi var olan bilgi ve beceri ile yapılandırmaları beklenmektedir. Bu nedenle öğrencilerin bilgiyi yapılandırmadan 
önce ön bilgilerinin ortaya çıkarılması önem teşkil etmektedir (Yahşi, 2006). Çünkü öğrencilerin ön bilgileri yoklanmadan, bu bilgiler üzerinde durulmadan öğretmen tarafından bilginin direkt aktarıldığı ve ayrıca kalıplaşmış sınavlarla öğrencilerin değerlendirildiği bir öğrenme ortamında yetişen bireylerin bilgiyi anlamlandırma ve yapılandırma konusunda güçlük çekmeleri muhtemeldir (Dalkıran, Kesercioğlu ve Boyacı, 2005). Bu açıdan düşünüldüğünde farklı öğrenme ve öğretme yöntemleri öğrencilerin kendi öğrenmelerine yardımcı olmalıdır (Günel, Uzoğlu ve Büyükkasap, 2009a). Yeni öğretim programlarında artık derslerin ezbercilikten uzak işlenilerek bol etkinlik kullanılması, daha eğlenceli, günlük hayatla ilişkilendirilerek hayatın içinde ve kullanılabilir olmasına önem verilmesine dikkat çekildiği görülmektedir. Sorgulamaya dayalı öğrenme yaklaşımı; yaparak ve düşünerek öğrenmeyi ön plana çıkaran ve gerçek yaşam bağlantılarıyla öğrencilerin ilgi ve meraklarını uyandıran bir yaklaşımdır (Duban, 2008). Araştırma ve sorgulamaya dayalı öğrenme, araştırma, sorgulama, bilgi analizi ve verileri yararlı bilgilere dönüştürme sürecidir (Perry and Richardson, 2001). Argümantasyon Tabanlı Bilim Öğrenme (ATBÖ) yaklaşımının temelinde araştırma-sorgulama stratejileri vardır ve düşünmeye önem veren süreçleri desteklemektedir (Hohenshell, 2004). ATBÖ araştırma ve sorgulamaya dayalı olarak fikirlerin ortaya atıldığı, kritik edildiği, değerlendirildiği, soru-iddia ve delil süreçlerinin işlenerek argüman oluşturulduğu, uzlaşma ve müzakere süreçlerinin gerçekleştiği bir yaklaşımdır (Akkuş, Günel ve Hand, 2007). ATBÖ yaklaşımınının uygulandığı sınıf ortamları öğrencilerin bilimsel çalışmaları arkadaşlarıyla birlikte yapmalarını ve yazma aktivitesini tartışarak yapmalarını sağlamaktadır (Hohenshell, 2004). Öğrenciler tartışmanın yararına inandıkları takdirde kaliteli tartışmalar yaparlar ve kaliteli tartışma yapabilen öğrenciler iddia ile kanıt ve iddia ile gerekçe arasındaki ilişkiyi muhakeme ederler ve bu sayede öğrencilerin kritik düşünmeleri de gelişir (Erduran, Ardaç ve Güzel, 2006).

Bilimsel tartışmada öğrenciler argümanlarını yapılandırırken bir bilim insanı gibi çalıştıkları için (veri toplar, gerekçe sunar, alternatif yorumları dikkate alır, tümevarımla sonuca ulaşır) öğrencilerin araştırma ve sorgulama yeteneği artmaktadır (Driver, Newton ve Osborne, 2000). Bilimsel tartışmanın öğrencilerde araştırma yeteneğini arttırdığına yönelik çok sayıda çalışma yapılmıştır (Druker, Chen ve Kelly, 1996; Yerrick, 2000). Bu çalışmalar; bilimsel tartışmanın öğrencilerin nedensel ilişkileri anlamaya yardımcı olma, test edilebilir hipotezler oluşturma, deneyler tasarlama, gerçek yaşam problemlerine çözümler getirme ve bilimsel araştırmayla ilgili yeteneklerinde olumlu değişiklikler oluşturduğunu göstermektedir. 
Ayrıca bilimsel tartışmada öğrenciler grup halinde çalıştıkları için bu grup çalışmaları sayesinde öğrencilerin sosyal etkileşimde bulunmaları ve işbirliği içinde olmaları amaçlanır.

Bilimsel tartışma ortamlarında zıt fikirlerin çürütülmesi, hipotezlerin yarıştırılması, gerekçelendirmelerin sunulması gibi uygulamalar, kavramsal değişim üzerinde etkili olmaktadır(Uluçınar, 2008). Ayrıca bilimsel tartışmalar sırasında öğrencilerin sahip oldukları alternatif fikirlerin sorgulanması ve bu süreçte zıt gerekçelerin ve bilimsel fikirlerin farkına varılması kavramsal değişim sürecini hızlandırmaktadır (Niaz, Alguilera, Maza ve Liendo, 2002). Osborne (2005) öğrencilerin sebepler kullanarak inandıklarını ispat etme, tahmin etme, delilleri değerlendirme, ve karşıt (zıt) argüman üzerinde düşünmenin, konuları kavramsal olarak öğrenmeye katkı sağlayacağını vurgulamıştır.

Tartışmaya (argümantasyon) dayalı öğretim yaklaşımında, öğrenciler zihinsel şemalarını ortaya koyup hem kendi hem de diğer öğrencilerin fikirlerini sorgulamaya çalışmaktadır. Aynı zamanda ortaya attıkları iddialarını savunmak için gerekçe ve kanıt kullanarak gerektiğinde yaptıkları çürütmelerle karşıt iddiaları geçersiz kılarak, üst düzey düşünme içeren, muhakeme etme ve bunları sözel olarak ifade etme becerilerini ortaya koyarlar. Bu açıdan bakıldığında tartışmaya dayalı yaklaşımın geleneksel yaklaşımdan üstün birçok yönü öne çıkmaktadır (Uluçınar, 2008).

ATBÖ yaklaşımı tartışmaya dayalı bir yaklaşım olduğundan toplumun ihtiyaç duyduğu sürekli araştıran sorgulayan ve ezbere değil tartışarak fikirlerini ileri süren yaratıcı bireylerin yetiştirilmesi ve geliştirilmesi açısından bu ihtiyaca cevap verecek nitelikte bir yaklaşım olması açısından da öneme sahiptir.

ATBÖ yaklaşımının uygulandığı öğrenme ortamında öğretmen öğrencileri gözlemler, veriler, iddialar ve kanıtlar arasında bağlantılar kurmasına teşvik eder ve diğer grup arkadaşlarının ileri sürdüğü iddiaları karşılaştırma yapmasına firsat sağlar. Ayrıca ATBÖ yaklaşımı öğrencilere deneyimlerinden sonra başlangıçtaki fikirlerinin nasıl değiştiğini göstermektedir (Hohenshell, 2004). Öğrenciler ATBÖ yaklaşımındaki kendi sorularını meydana getirme, akran grup tartışmalarına katılım ve yazma işlemiyle kavramlar arasında bağlantı kurma aktiviteleriyle anlamalarının arttığını ifade etmişlerdir. (Hand, Wallace \& Yang, 2004). ATBÖ yaklaşımında öğretmen çoğunlukla öğrenci merkezli aktiviteleri planlar ve öğrencileri kendilerini özgürce ifade edebilmeleri yönünde cesaretlendirir.

Argümantasyonun yapısını oluşturan bileşenler Toulmin (1958) tarafından aşağıdaki şekilde görüldüğü gibi belirlenmiştir.

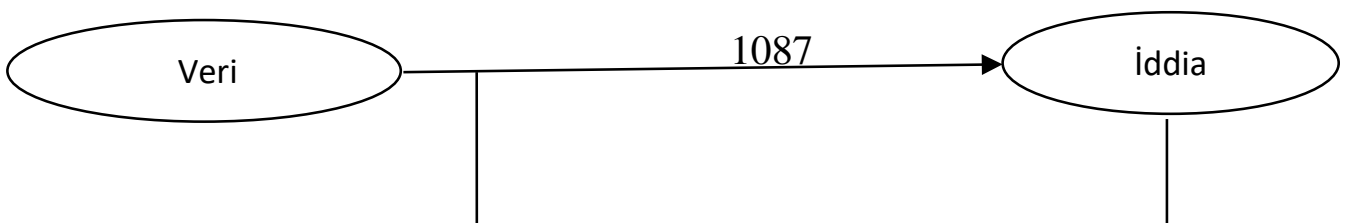


Argümantasyon yapısının oluşabilmesi için öğrencilerin veriye bağlı olarak kendi iddialarını ortaya atmaları, bu iddia ile veri arasında geçerli ve kabul edilebilir gerekçeler kurabilmeleri gerekir. Ayrıca argümantasyon sürecinde bu iddialarına itirazlar (çürütmeler) geldiğinde bunları daha genel formal bilgilerle destekleyebilmeleri istenir (Aldağ, 2006; Sampson and Clark, 2008). Bu süreç içerisinde öğretmenin öğrencilerini bilişsel olarak yönlendirebilmesi oldukça önemlidir (Carpenter, Fennema and Franke, 1996).

ATBÖ yaklaşımının uygulandığı sınıf ortamıyla geleneksel yaklaşımının uygulandığı sınıf ortamının karşılaştırılarak fen derslerinde başarıya etki ve fene karşı tutumun incelendiği çalışmalar incelenirse; Kaya (2005) tarafından yapılan çalışmada da tartışma teorisine dayalı eğitim alan öğrencilerin, geleneksel yaklaşımla eğitim alan öğrencilere göre daha başarılı oldukları ve istatistiksel olarak anlamlı bir farkın olduğu tespit edilmiştir. Yeşiloğlu (2007)'nin yürüttüğü çalışmada bilimsel tartışma modeli ile eğitim verilen öğrencilerin başarılarının ve kavramsal değişimlerinin geleneksel öğretim ile eğitim gören öğrencilerden daha yüksek olduğu ortaya çıkmıştır. Ceylan (2010), biyoloji öğretmen adayları ile Argümantasyon Tabanlı Bilim Öğrenme yaklaşımını Bitki Fizyolojisi Laboratuarı dersinde uygulayarak, bu yöntemin öğrencilerin akademik başarısı üzerindeki etkisini incelemek amacıyla gerçekleştirdiği çalışma sonuçlarına göre deney grubunun ön test ve son test sonuçları arasında istatistiksel açıdan anlamlı bir farklılığın bulunduğunu, ATBÖ yaklaşımının öğrenci başarısını olumlu etkilediğini ortaya koymuştur.

Bu çalışmada ATBÖ yaklaşımının matematik dersinde uygulanmasının öğrencilerin matematik kavramlarını ezber yapmadan, kavrayarak öğrenmelerinin yanında kendi yaratıcılıklarının 
farkına varabilecekleri örnek bir öğrenme ortamını tecrübe etmeleri düşünülmektedir. Bu düşünceden hareketle araştırmamızın amacı argümantasyon tabanlı bilim öğrenme yaklaşımının 9. sınıf öğrencilerinin fonksiyonlar konusundaki başarılarına olan etkisini incelemektir.

\section{Yöntem}

\section{Problem Cümlesi}

$\mathrm{Bu}$ çalışmada Argümantasyon Tabanlı Bilim Öğrenme Yaklaşımının 9. Sınıf öğrencilerinin matematik başarılarını nasıl etkilediği araştırılmıştır.

\section{Araştırma Deseni}

Çalışmada nicel yöntem kullanılmıştır. Çalışma, tek grup ön test-son test zayıf deneysel araştırma deseninden oluşmaktadır. Karasar (2007) tek grup ön test son test modelinde gelişi güzel seçilmiş bir gruba bağımsız değişken uygulandığını belirtmiş, hem deney öncesi (ön test), hem de deney sonrası (son test) ölçmelerin olduğunu belirtmiştir. Bu çalışmada rasgele bir 9.sınıf şubesi seçilerek uygulama öncesi ve uygulama sonrası başarı testi kullanıldığı için bu desenin uygun olduğuna karar verilmiştir.

\section{Çalışma Grubu}

Araştırma Bayburt Fen Lisesi 2012-2013 öğretim yılı güz döneminde 9. sınıfta öğrenim gören 11 kı ve 11 erkek öğrenci olmak üzere toplam 22 öğrenci ile yürütülmüştür. Öğrencilerin hepsi ilköğretimde benzer eğitim almış oldukları ve SBS'den belli bir taban puanla fen lisesine yerleştikleri dikkate alınırsa oldukça homojen bir grup olduğu söylenebilir. Öğrencilerin seçiminde seçkisiz olmayan örnekleme yaklaşımlardan biri olan amaçsal örnekleme yöntemi kullanılmıştır. Amaçsal örnekleme olasılığa dayanmayanseçkisiz olmayan bir örnekleme türüdür(Büyüköztürk, 2008). Fen Lisesi öğrencilerinin verimli ve kaliteli tartışmalar yapabileceği düşünüldüğü için bu lise seçilmiştir. Fen Liseleri; matematik ve fen bilimleri alanlarında gereksinim duyulan üstün nitelikli bilim adamlarının yetiştirilmesine kaynaklık etmeyi, öğrencileri araştırmaya yöneltmeyi, bilimsel ve teknolojik gelişmeler ile yeni buluşlara ilgi duyanların çalışacakları ortamı ve koşulları hazırlamayı, yeni teknolojileri kullanabilen, yeni bilgiler üretebilen ve projeler hazırlayabilen bireyler yetiştirmeyi amaçlayan okullardır (MEB, 2009). 


\section{Uygulama}

ATBÖ yaklaşımının uygulanacağı sınıf ortamında öğrencilerin veriye bağlı olarak kendi iddialarını ortaya atmaları, bu iddia ile veri arasında geçerli ve kabul edilebilir gerekçeler kurabilmeleri ve bu süreçte ortaya attıkları iddialarına itirazlar geldiğinde bunları daha geçerli bilgilerle destekleyebilmeleri istenir ve beklenir. Bu süreçte öğretmenin öğrencilerini bilişsel olarak yönlendirebilmesi oldukça önemlidir. İlk olarak öğrencilerin ezbere başvurmaksızın öğrenecekleri konunun kavramları ile ilgili sorgulanması; bu sayede sahip oldukları fikirleri önce grup içinde arkadaşlarıyla tartışarak ortak bir karara varmaları; vardıkları ortak karar nihayetinde bir iddia oluşturarak diğer gruplara bu iddialarını sunmaları ve her grubun iddiası dinlendikten sonra ileri sürülen iddiaları sağlam delillere dayandırarak çürütmeleri yahut desteklemeleri beklenmektedir. Bir süre tartışmadan sonra kendilerine bir etkinlik verilerek tekrar tartışmaları istenip ve nihayetinde tartışarak istenen şeye hazır bilgiden değil kendilerinin düşünerek ve tartışarak ulaşmaları sağlanmaya çalışılmıştır. Bu süreç esnasında araştırmacı çoğunlukla "Arkadaşlarınızın fikrine katılıyor musunuz?, Neden?, Nasıl” gibi sorularla öğrenciler arasında müzakere süreçlerinin oluşmasına katkıda bulunmuştur. Bütün grupların tartışmaları bittikten sonra araştırmacı soru-cevap yöntemini kullanarak genel bir toparlama yoluna gitmiş ve yapılan etkinliklerin dersin ana fikri ile ilişkilendirilmesini sağlamıştır.

\section{Verilerin Toplanması}

Çalışmanın verileri Fonksiyon Başarı Testi ve Matematik Muhakeme Yaklaşımı Öğrenci Şablonu kullanılarak toplanmıştır.

\section{Fonksiyon Başarı Testi:}

Çalışmada verilerin toplanması için Fonksiyon Başarı Testi (FBT) kullanılmıştır. Çalışma için geliştirilen testin ilk hali 20 açık uçlu sorudan oluşmaktadır. Fonksiyonlar konusuyla ilgili geçmiş yıllarda ÖSS-LYS-YGS sınavında çıkmış sorular bir araya getirilerek bir soru havuzu oluşturulmuştur. Soruların hangilerinin kullanılacağı belirlenirken konu ile ilgili kazanımlar ve çalışmanın amacı kriter olarak alınmıştır ve belirtke tablosu hazırlanmıştır. $\mathrm{Bu}$ kriterlere bağlı olarak belirlenen sorular aynen kullanılmamış, çoktan seçmeli olarak sorulmuş sorular açık uçlu soru haline dönüştürülerek kullanılmıştır. Oluşturulan belirtke tablosuna göre 20 adet soru belirlenmiştir. Testin pilot çalışması 10. sınıfta öğrenim gören 50 
kişilik öğrenci grubuna uygulanmış ve her öğrencinin testten elde ettiği toplam puan hesaplanmıştır. Hesaplanan bu puanlar büyükten küçüğe doğru sıralanmış daha sonra öğrenciler 3 gruba ayrılmış, üst grup 15, orta grup 20 ve alt grup 15 öğrenciden oluşmuştur. Oluşan bu gruplara göre testin maddeler için ayırt edicilik ve güçlük indeksleri hesaplanmıştır. Özçelik (1989)'a göre madde güçlük indeksi 0,20 den düşük olanlar kullanılamaz, 0,20-0,30 olanlar kullanılabilir, 0,30-0,40 olanlar iyi, 0,40 dan büyük olanlar iyi soru olarak tasnif edildiğinden madde güçlük indeksi 0,20 nin altında olan sorular çıkarılmıştır. Testte yer alan 2,6,13,15 ve 19. sorular madde analizinde ayırt edicilikleri düşük olduğu için çıkarılmıştır. Testin geçerliliğini sağlamak için uzman görüşüne başvurulmuştur. 3 matematik eğitimi uzmanı ve uygulama yapılan lisede görev yapan 2 matematik öğretmeni tarafından sorular incelenmiş ve görüşleri alınarak kapsam geçerliliği sağlanmaya çalışılmıştır.

Açık uçlu soruların madde analizleri aşağıdaki gibi yapılmıştır (Bayrakçeken, 2008).

P:Madde güçlük indeksi ve D:madde ayırıcılık indeksi

olmak üzere 4. sorunun madde analizleri

$$
\begin{aligned}
& P=\frac{(47+19)}{30 * 4}=\frac{66}{120}=0,55 \\
& D=\frac{(47-19)}{15 * 4}=\frac{28}{60}=0,466
\end{aligned}
$$

şeklinde hesaplanmıştır.

Oluşturulan fonksiyon başarı testindeki 20 açık uçlu sorunun madde analizlerine Tablo 3.2' de yer verilmiştir.

Tablo 3.2.

\begin{tabular}{|c|c|c|c|c|c|c|c|c|c|}
\hline SORU & GRUP & $\begin{array}{l}\tilde{\Xi} \\
\stackrel{\Xi}{\Xi} \\
\forall\end{array}$ & 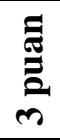 & $\begin{array}{l}\text { 䒿 } \\
\text { ล } \\
\text { N }\end{array}$ & 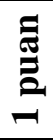 & 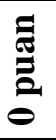 & $\begin{array}{c}\text { TOPLAM } \\
\text { PUAN }\end{array}$ & $\mathbf{P}$ & D \\
\hline \multirow{2}{*}{1} & Üst Grup & 14 & 1 & 0 & 0 & 0 & 59 & \multirow{2}{*}{0,883} & \multirow{2}{*}{0,20} \\
\hline & Alt Grup & 9 & 2 & 2 & 1 & 1 & 47 & & \\
\hline \multirow{2}{*}{2} & Üst Grup & 15 & 0 & 0 & 0 & 0 & 60 & \multirow{2}{*}{0,958} & \multirow{2}{*}{0,08} \\
\hline & Alt Grup & 11 & 3 & 1 & 0 & 0 & 55 & & \\
\hline \multirow{2}{*}{3} & Üst Grup & 13 & 1 & 1 & 0 & 0 & 57 & \multirow{2}{*}{0,800} & \multirow{2}{*}{0,30} \\
\hline & Alt Grup & 6 & 3 & 2 & 2 & 2 & 39 & & \\
\hline \multirow{2}{*}{4} & Üst Grup & 9 & 3 & 0 & 2 & 1 & 47 & \multirow{2}{*}{0,550} & \multirow{2}{*}{0,46} \\
\hline & Alt Grup & 3 & 1 & 1 & 2 & 8 & 19 & & \\
\hline 5 & Üst Grup & 12 & 2 & 0 & 1 & 0 & 59 & 0,741 & 0,35 \\
\hline
\end{tabular}

Fonksiyon Başarı Testi Açık Uçlu Soruların Madde Analizleri 


\begin{tabular}{|c|c|c|c|c|c|c|c|c|c|}
\hline & Alt Grup & 6 & 2 & 1 & 2 & 4 & 34 & & \\
\hline \multirow{2}{*}{6} & Üst Grup & 4 & 0 & 1 & 2 & 8 & 20 & \multirow{2}{*}{0,266} & \multirow{2}{*}{0,133} \\
\hline & Alt Grup & 2 & 0 & 1 & 2 & 11 & 12 & & \\
\hline \multirow{2}{*}{7} & Üst Grup & 14 & 1 & 0 & 0 & 0 & 59 & \multirow{2}{*}{0,833} & \multirow{2}{*}{0,30} \\
\hline & Alt Grup & 8 & 1 & 2 & 2 & 2 & 41 & & \\
\hline \multirow{2}{*}{8} & Üst Grup & 12 & 1 & 1 & 1 & 0 & 54 & \multirow{2}{*}{0,758} & \multirow{2}{*}{0,283} \\
\hline & Alt Grup & 7 & 1 & 2 & 2 & 3 & 37 & & \\
\hline \multirow{2}{*}{9} & Üst Grup & 11 & 1 & 0 & 1 & 2 & 48 & \multirow{2}{*}{0,633} & \multirow{2}{*}{0,333} \\
\hline & Alt Grup & 5 & 1 & 1 & 3 & 5 & 28 & & \\
\hline \multirow{2}{*}{10} & Üst Grup & 10 & 3 & 0 & 1 & 1 & 50 & \multirow{2}{*}{0,625} & \multirow{2}{*}{0,416} \\
\hline & Alt Grup & 4 & 1 & 2 & 2 & 6 & 25 & & \\
\hline \multirow{2}{*}{11} & Üst Grup & 9 & 2 & 1 & 1 & 2 & 45 & \multirow{2}{*}{0,5} & \multirow{2}{*}{0,5} \\
\hline & Alt Grup & 3 & 0 & 1 & 1 & 10 & 15 & & \\
\hline \multirow{2}{*}{12} & Üst Grup & 9 & 1 & 1 & 1 & 3 & 42 & \multirow{2}{*}{0,433} & \multirow{2}{*}{0,533} \\
\hline & Alt Grup & 2 & 0 & 0 & 2 & 11 & 10 & & \\
\hline \multirow{2}{*}{13} & Üst Grup & 2 & 0 & 1 & 5 & 7 & 15 & \multirow{2}{*}{0,175} & \multirow{2}{*}{0,15} \\
\hline & Alt Grup & 0 & 1 & 1 & 1 & 12 & 6 & & \\
\hline \multirow{2}{*}{14} & Üst Grup & 10 & 2 & 1 & 1 & 1 & 49 & \multirow{2}{*}{0,525} & \multirow{2}{*}{0,583} \\
\hline & Alt Grup & 3 & 0 & 0 & 2 & 10 & 14 & & \\
\hline \multirow{2}{*}{15} & Üst Grup & 15 & 0 & 0 & 0 & 0 & 60 & \multirow{2}{*}{0,933} & 0133 \\
\hline & Alt Grup & 11 & 2 & 1 & 0 & 1 & 52 & & כ, נט, \\
\hline 16 & Üst Grup & 12 & 2 & 1 & 0 & 0 & 56 & 0791 & 0783 \\
\hline 10 & Alt Grup & 9 & 0 & 1 & 1 & 4 & 39 & D, & $0, \angle O J$ \\
\hline 17 & Üst Grup & 10 & 1 & 1 & 2 & 1 & 47 & 0441 & 0683 \\
\hline 17 & Alt Grup & 0 & 1 & 1 & 1 & 12 & 6 & 0,441 & (000 \\
\hline 18 & Üst Grup & 9 & 3 & 1 & 1 & 1 & 41 & 0366 & 0633 \\
\hline 10 & Alt Grup & 0 & 0 & 0 & 3 & 12 & 3 & 0,500 & \\
\hline 19 & Üst Grup & 1 & 0 & 2 & 5 & 7 & 13 & 0133 & 0166 \\
\hline 10 & Alt Grup & 0 & 0 & 1 & 1 & 13 & 3 & נד, & 0,100 \\
\hline 20 & Üst Grup & 9 & 2 & 1 & 2 & 1 & 45 & 0433 & 0633 \\
\hline 20 & Alt Grup & 0 & 1 & 1 & 2 & 11 & 7 & 0,435 & \\
\hline
\end{tabular}

Madde analizi yapıldıktan sonra bazı soruların $(2,6,13,15,19)$ çıkarılmasıyla 15 açık uçlu soru içerecek şekilde fonksiyon başarı testinin son hali oluşturulmuştur. Pilot uygulamadan elde edilen veriler için güvenirlik analizi yapılmış ve cronbach alfa değeri .709 olarak bulunmuştur. Pilot çalışması sonucunda testin bir saatlik süre içinde uygulanmasına karar verilmiştir.

15 açı uçlu sorudan oluşan Fonksiyon Başarı Testi uzman görüşleri alınarak 4 kategoriye ayrılmıştır. Kategoriler 15 açık uçlu soru için A kategorisinde 4, B kategorisinde 3, C kategorisinde 4 ve D kategorisinde 4 soru şeklinde oluşturulmuştur. A kategorisi; daha çok basit düzeyde işlemsel soruları içeren kategoridir. B kategorisi; temel bilgilerin kavranmasıyla ilgili A kategorisindeki sorulara göre biraz daha zor sorular içermektedir. C kategorisi; grafik sorularını içeren kategoridir ve D kategorisi ise daha çok muhakeme tipi soruları içeren kategoridir. 


\section{Matematik Muhakeme Yaklaşımı Öğrenci Şablonu:}

Akkuş (2007) ve Akkuş ve Hand (2011) tarafindan geliştirilen Matematik Muhakeme Yaklaşımı (MMY) öğrenci şablonu problem çözme, yazma ve argümantasyon üzerine kurulu bir şablondur. Matematik eğitimcileri matematik sınıflarında argümantasyon ve muhakemeyi yazma aktiviteleriyle birleştiren uygulamaları desteklemeye çalışmaktadır (Cross, 2009; NCTM, 2000; Ernest, 1998). Araştırma grubundaki öğrenciler fonksiyonlar konusu için MMY öğrenci şablonunu tartışma sürecinde ve sonunda içeriğinde var olan bölümlere uygun olarak doldurmuşlardır. Bu şablonda problemi anlama (problemde verilenler ve veriler arasındaki ilişki, matematiksel ifade yazabilme, probleme uygun şekil veya tablo çizebilme), probleme çözüm önerisi sunma, problemi çözme aşaması (problemi çözme aşamasında yapılanlar, zorlanılan noktalar), sebepler (kullanılan işlemlerin nedeni, çözüm mantıklı ve tutarlımı, başka çözüm yolu var mı ), başkaları ne diyor? (grup içi ve dışılla karşılaştırma sonu benzerlikler ve farklılıklar) ve değerlendirme (fikirler nasıl değişti?) bölümleri bulunmaktadır.

\section{Verilerin Analizi}

Fonksiyon Başarı Testi için cevap anahtarı oluşturulduktan sonra her bir sorunun doğru cevabına 4, yanlış cevabına 0 değeri verilmiştir. O halde tüm sorulara doğru cevap veren kaç puan alır. Değerlendirme hangi puan aralığındadır. Lütfen bunlara vurgu yapınız. Açık uçlu soruların değerlendirilmesinde Milli Eğitim Bakanlığı tarafından hazırlanan matematik öğretim programında verilen problem çözme için bütüncül değerlendirme anahtarı kullanılmıştır. Fonksiyon Başarı Testi için ön test-son testten elde edilen verilerin çözümlenmesinde SPSS 18.0 paket programı kullanılmıştır. Parametriğin şartları olan normallik şartı için çarpıklık (skewness) ve basıklık (kurtosis) değerlerine bakılmıştır ve bu değerler -1 ve +1 arasında olup peki kaç? Eşleştirilmiş örneklem t-testi yapılmıştır. Kategorilere ayrıştırılan Fonksiyon Başarı Testi'nin çarpıklık (skewness) ve basıklık (kurtosis) değerleri -1 ve +1 arasında olup Eşleştirilmiş örneklem t-testi kullanılmıştır.

Kategorilere ayrılan FBT için analiz öncesi gerekli varsayımların sağlanıp sağlanmadığının ve öncelikle verilerin normal dağılıp dağılmadığının belirlenmesi için basıklık ve çarpıklık değerleri hesaplanmış ve boxplots grafikleri çizilmiştir. Çizilen boxplot grafiklerinin D kategorisinde bir aşırı değer tespit edilmiştir ve normalliği etkilediği için bu değer en düşük bir alt değerle değiştirilmiştir. Yeniden hesaplanan basıklık ve çarpıklık 
değerleri verilerin her bir kategori için normal dağıldığına işaret etmektedir. Ayrıca varyansların homojenliği için yapılan levene testi de bu varsayımın .05 düzeyinde karşılandığını göstermektedir $(\mathrm{F}(3,84)=2,198 ; \mathrm{p}=0,094)$. Her bir kategoriye öğrencilerin ortalamaları arasında anlamlı bir farklılık olup olmadığını tespit etmek için eşleştirilmiş örneklem t testi yapılmıştır.

Öğrencilerin öğrenme amaçlı yazma aktivitesi olarak tamamladıkları MMY raporlarını değerlendirmek için Choi (2008; s. 128-139) tarafından geliştirilen ATBÖ rapor değerlendirme şablonundan esinlenilmiştir. $\mathrm{Bu}$ çalışmada kullanılan MMY raporlarını değerlendirme puanlama anahtarı 5 araştırmacı (3 araştırma görevlisi, 2 yardımcı doçent) tarafından oluşturulmuştur. Puanlama anahtarının güvenilirliği için bir öğrencinin raporu, puanlama anahtarını geliştiren 4 araştırmacı tarafından ayrı ayrı değerlendirilmiş ve değerlendirmelerde tutarlılık sağlanmaya çalışılmıştır. Bu değerlendirme işlemine tutarlılık sağlanıncaya kadar devam edilmiş ve sonra araştırmacı tarafından bütün MMY raporları MMY puanlama anahtarına göre puanlanmıştır.

\section{Bulgular}

Bu bölümde çalışma sonucunda elde edilen bulgulara yer verilmiştir.

\section{Fonksiyon Başarı Testinden Elde Edilen Bulgular:}

Tablo 2'de ATBÖ yaklaşımının kullanıldığı çalışma grubuna uygulanan Fonksiyon Başarı Testi’nden, elde edilen verilere dayalı bulgular ve yorumlanması yer almaktadır.

Tablo 2. Fonksiyon Başarı Testi Öntest-Sontest Puanlarına Ait Eşleştirilmiş Örneklem t testi Sonuçları

\begin{tabular}{lcccccc}
\hline Ölçüm & $\mathbf{N}$ & $\overline{\boldsymbol{X}}$ & SS & Sd & $\mathbf{T}$ & $\mathbf{p}$ \\
\hline Öntest & 22 & 7.23 & 5.94 & 21 & -19.152 & $.000^{*}$ \\
Sontest & 22 & 42.77 & 8.60 & & & \\
\hline${ }^{*}<.05$ & & & & &
\end{tabular}

Uygulama grubunda başarı testinin ön test ve son test olarak uygulanmasından elde elden veriler ön test ve son test arasındaki olası farkları ortaya çıkarmak amacıyla istatistiksel analize tabi tutulmuştur. Yapılan istatistiksel analiz sonuçları, öğrencilerin ATBÖ yaklaşımı uygulanmadan önce başarı testinden aldıkları puanların ortalaması 7.23 iken uygulamadan sonra aynı testten aldıkları puanların ortalaması 42.77 ye yükseldiğini ortaya çıkarmıştır. Başarı 
ön testi ve son testi arasında istatistiksel olarak anlamlı bir farklılığın olup olmadığını tespit etmek için kullanılmasına karar verilen eşleştirilmiş örneklem t testi yapılmadan önce gerekli varsayımların sağlanıp sağlamadığını belirlemek için hesaplanan çarpıklık ve basıklık değerleri -1 ve +1 arasında olup verilerin normal dağıldığına işaret etmektedir. Gerekli varsayımların sağlandığı belirlendikten sonra yapılan analizin sonuçları, başarı ön testi ve son testi arasında .05 anlamlılık düzeyinde istatistiksel olarak anlamlı bir fark olduğunu ortaya koymuştur $(\mathrm{p}=.00<.05)$. Başka bir ifadeyle, matematik öğretiminde kullanılan ATBÖ yaklaşımının öğrencilerin fonksiyonlar konusundaki başarılarını arttırmada başarılı bir yöntem olduğu söylenebilir.

Tablo 3 'te kategorilere ayrılan Fonksiyon Başarı testine ilişkin ön test-son tesr puan ortalamalarına ait eşleştirilmiş örneklem $\mathrm{t}$ testi sonuçları verilmiştir.

Tablo 3. Kategorilere Ayrılan Fonksiyon Başarı Testi Öntest-Sontest Puan Ortalamalarına Ait Eşleştirilmiş Örneklem t testi Sonuçları

\begin{tabular}{|c|c|c|c|c|c|}
\hline Ölçüm & $\mathbf{N}$ & $\bar{X}$ & SS & $T$ & $\mathbf{P}$ \\
\hline Aö & 22 & 4.00 & 3.48 & \multirow{2}{*}{-10.34} & \multirow{2}{*}{.000} \\
\hline As & 22 & 13.55 & 3.38 & & \\
\hline Bö & 22 & .91 & 1.51 & \multirow{2}{*}{-10.15} & \multirow{2}{*}{.000} \\
\hline Bs & 22 & 8.09 & 3.25 & & \\
\hline Cö & 22 & .72 & 1.16 & \multirow{2}{*}{-12.32} & \multirow{2}{*}{.000} \\
\hline Cs & 22 & 10.81 & 4.05 & & \\
\hline Dö & 22 & .18 & .85 & \multirow{2}{*}{-14.60} & \multirow{2}{*}{.000} \\
\hline Ds & 22 & 11.77 & 3.61 & & \\
\hline
\end{tabular}

Aö: A kategorisi ön test, As: A kategorisi son test, Bö: B kategorisi ön test, Bs: B kategorisi son test, Cö: C kategorisi ön test, Cs: C kategorisi son test, Dö: D kategorisi ön test, Ds: D kategorisi son test

Dört kategoriden oluşan Fonksiyon Başarı Testinde öğrencilerin her bir kategoriden aldıkları puanların ortalamaları hesaplanmıştır ve her bir kategorinin ön testi ile son testinden öğrencilerin aldıkları puanlar arasında anlamlı bir farklılığın olup olmadığını belirlemek için eşleştirilmiş örneklem $\mathrm{t}$ testi yapılmıştır. Tablo 3'e bakıldığında, araştırmaya katılan öğrencilerin A alt boyutunun ön testinden aldıkları puanların ortalamalarının 4.00 olduğu son test puan ortalamaları 13.55 olduğu görülmektedir. Bu kategoride öğrencilerin ortalamaları arasında anlamlı bir farklılık olup olmadığını tespit etmek için yapılan eşleştirilmiş örneklem t testi sonuçlarına göre son test lehine istatistiksel olarak anlamlı bir farklılık olduğu tespit edilmiştir $(\mathrm{p}=.00<.05)$. B alt boyutunun sonuçlarına bakıldığında ise, öğrencilerin ön test puan ortalamasının 0.91 iken son test puan ortalamasının 8.09'a yükseldiği görülmektedir. Aradaki 
istatistiksel farkı belirlemek için yapılan analiz sonucunda, tespit edilen anlamlı farklılığın son test lehine olduğu ortaya çıkmıştır $(\mathrm{p}=.00<.05)$. Bir diğer alt boyut olan $\mathrm{C}$ boyutunda ise, öğrencilerin ön test puan ortalamaları 0.72 olarak belirlenirken son test puan ortalamaları 10.81 olarak hesaplanmıştır. Yine aynı şekilde, gelişimin istatistiksel açıdan önemli olup olmadığını belirlemek için yapılan istatistiksel analiz sonuçları, son test sonuçlarının son test lehine olduğunu göstermektedir $(\mathrm{p}=.00<.05)$. Son olarak, D alt boyutu için yapılan analizlere bakıldığında, bu alt boyutun ön testinden öğrencilerin aldığı puan ortalamasının 0.18 olduğu görülürken son testinden aldıkları puan ortalamasının 11.77 olduğu görülmüştür. Yapılan eşleştirilmiş örneklem t testi sonuçları da, ön test ile son test arasında son test lehine istatistiksel olarak anlamlı bir fark olduğunu ortaya koymuştur $(p=.00<.05)$.

Kategoriler arasında ön test- son test puanlarına bakıldığında, son test ortalama puanı en yüksek olan A kategorisi olmakla birlikte; bu kategorinin basit düzeyde işlemsel sorular içerdiği için yüksek olduğu söylenebilir. İkinci olarak son test ortalama puanı yüksek olan kategori ise D kategorisidir. Bu kategori muhakeme tipi soruları içermektedir.

Tablo 4'te kategorilere ayrilan FBT'nin son test puan ortalamaları ve standart sapma değerleri verilmiştir.

Tablo 4. Kategorilere Ayrılan FBT Sontest Puan Ortalamaları ve Standart Sapma Değerleri

\begin{tabular}{llll}
\hline $\begin{array}{l}\text { Alt } \\
\text { Kategoriler }\end{array}$ & $\mathbf{N}$ & $\overline{\boldsymbol{X}}$ & Ss \\
\hline Akategorisi & 22 & 2.70 & 1.08 \\
\hline B kategorisi & 22 & 2.70 & 1.08 \\
\hline C kategorisi & 22 & 2.71 & 1.01 \\
\hline D kategorisi & 22 & 3.02 & 0.68 \\
\hline Toplam & 88 & 2.76 & 1.01 \\
\hline
\end{tabular}

$\mathrm{N}=$ ögrenci sayıs1; $\bar{X}=$ Ortalama; ss= Standart Sapma

Başarı testinde yer alan her bir alt kategori için hesaplanan ortalama ve standart sapma değerleri tablo 4.3' te yer almaktadır. Tablo 4'e bakıldığında öğrencilerin başarı son testinin A(basit düzeyde işlemsel sorular içeren) kategorisinden ve B kategorisinden(temel bilgilerin kavranması) aldıkları puanların ortalamasının 2.70, C kategorisinden(grafik soruları) aldıkları puanların ortalaması 2.71, D kategorisinden(muhakeme soruları) aldıkları puanların ortalamasının ise 3.02 olduğu görülmektedir. Bu düzeylerin standart sapma değerleri ise sırasıyla 1.08, 1.08, 1.01 ve 0.68 olarak hesaplanmıştır. 
Tablo 5' te kategorilere ayrılan FBT’nin son test puanlarına yönelik tek yönlü varyans analiz sonuçları verilmiştir.

Tablo 5. Kategorilere Ayrılan FBT Sontest Puan Ortalamalarına Yönelik Tek Yönlü Varyans Analizi Sonuçları

\begin{tabular}{lccccc}
\hline & $\begin{array}{c}\text { Kareler } \\
\text { toplamı }\end{array}$ & $\begin{array}{c}\text { Serbestlik } \\
\text { derecesi }\end{array}$ & $\begin{array}{c}\text { Kareler } \\
\text { ortalaması }\end{array}$ & F & $\mathbf{p}^{*}$ \\
\hline Gruplar arası & 1.733 & 3 & 0.578 & 0.602 & .616 \\
\hline Grup içi & 80.596 & 84 & 0.959 & & \\
\hline Toplam & 82,329 & 87 & & \\
$\mathrm{p}^{*<.05}$ & & & &
\end{tabular}

Uygulanan yöntemin başarı testinde yer alan dört farklı kategoriden hangisinin üzerinde daha etkili olduğunu belirlenmek için yapılan tek yönlü varyans analizi (one-way ANOVA) sonuçları uygulanan yöntemin alt kategorilerdeki başarıyı arttırma açısından gruplar arasında anlamlı bir farklılık göstermediğini ortaya koymuştur ( $p>.05)$. Başka bir ifadeyle, elde edilen sonuçlar uygulanan argümantasyon temelli eğitim yönteminin basit işlemsel soruları içeren, temel bilgilerin kavranması, grafik soruları ve muhakeme sorularını içeren kategoriler olmak üzere her bir alt kategoride yer alan başarı türünü etkilemede aynı düzeyde etkiye sahip olduğu şeklinde yorumlanabilir.

\section{Matematik Muhakeme Yaklaşımı Öğrenci Raporlarından Elde Edilen Bulgular:}

Tablo 6'da fonksiyonlar konusu işlenirken öğrencilerden tartışma esnasında ve sonunda doldurmaları istenen MMY raporları toplam puanları ile FBT son testi toplam puanları arasındaki ilişki verilmiştir.

Tablo 6. MMY Puanları ile FBT Son Test Puanları Korelasyon Sonuçları

\begin{tabular}{llcr}
\hline & & MMY.rapor & FBT \\
\hline MMY.rapor & Pearson Korelasyon(r) & 1 & .614 \\
& Sig.(2-tailed) & & $.002^{* *}$ \\
& $\mathrm{~N}$ & 22 & 22 \\
\hline FBT & Pearson Korelasyon(r) & .614 & 1 \\
& Sig.(2-tailed) & $.002^{* *}$ & \\
& $\mathrm{~N}$ & 22 & 22 \\
\hline
\end{tabular}

Öğrencilerin fonksiyonlar konusunda MMY raporlarından aldıkları toplam puanları ile fonksiyonlar konusu son test toplam puanları arasında pearson korelasyonuna bakılmıştır. 
Korelasyon sonuçları Tablo 4.5'te verilmiştir. Korelasyon katsayısının 0.700-1.000 arasında olması, yüksek; 0.700- 0.300 arasında olması, orta; 0.300- 0.000 arasında olması düşük düzeyde bir ilişki olduğu şeklinde tanımlanır (Büyüköztürk, 2004). Bulgular MMY raporları ile fonksiyon son test toplam puan arasında olumlu, orta düzeyde ve anlamlı bir ilişki olduğunu göstermektedir $(\mathrm{r}=.614, \mathrm{p}<.05)$. Bir başka deyişle, öğrencilerin tamamlamış oldukları MMY raporları; fonksiyon son testinin $\left(r^{2}=0,37\right) \% 37$ sini açıklamaktadır.

\section{Sonuç ve Tartışma}

Sınırlı sayıda öğrenci ile yürütülen bu çalışmada örneklemin az olması ve çalışmada yürütülen konunun darlığg önemli sınırlılıklar olarak görünmektedir. 22 öğrenci ve matematikte bir konu ile yürütülen çalışmanın sonuçları değerlendirilirken bu sınırlılıkların göz önünde bulundurulması gerekmektedir.

Ortaöğretim 9.sınıf matematik dersinde fonksiyonlar konusunun ATBÖ yaklaşımıyla işlenerek bu yaklaşımın fonksiyonlar konusundaki başarıya etkisinin incelendiği bu araştırmada tek gruba uygulanan ATBÖ yaklaşımının fonksiyonlar konusundaki başarıya olumlu bir etkisi olduğu tespit edilmiştir.

ATBÖ yaklaşımı temel alınarak işlenilen fonksiyonlar konusu öncesinde ve sonrasında öğrencilere uygulanan başarı testi sonuçları değerlendirildiğinde son test lehine anlamlı bir farklılığın olduğu görülmüştür $(\mathrm{p}=.00<.05)$. Elde edilen bulgular incelendiğinde öğrencilerin ön test puan ortalaması 7.23 iken son test puan ortalaması 42.77'ye yükselmiştir. Başka bir ifadeyle, matematik öğretiminde kullanılan ATBÖ yaklaşımının öğrencilerin fonksiyonlar konusundaki başarılarını arttırmada etkili bir yöntem olduğu söylenebilir. Rudd, Greenbowe, Hand ve Legge, (2001) kimya dersindeki denge konusunda uygulama grubuna ATBÖ yaklaşımıyla ders işleyerek son test lehine anlamlı bir farklılık tespit etmişlerdir. Yeşiloğlu (2007)’nun gazlar konusunda deney grubuna tartışma modeli ile işlenmiş ve kontrol grubuna göre yüksek başarı tespit edilmiştir. Erkol, Kışoğlu ve Büyükkasap (2010), üniversite fen bilgisi birinci sınıf öğrencileri ile gerçekleştirdikleri uygulamalarında ATBÖ yaklaşımı ve geleneksel yaklaşımı öğrencilerin mekanik konularını anlamaları bakımından karşılaştırmışlardır ve öğrencilerin mekanik konuları kavramsal düzeyde ATBÖ yaklaşımıyla 
daha iyi anladıklarını göstermiştir. Benzer olarak Günel, Kabataş-Memiş, Yeşildağ, Biber, Okçu ve Şahin (2010) ATBÖ yaklaşımının üniversite düzeyinde öğrencilerin genel fizik laboratuarı dersindeki başarıları üzerine etkisini araştırmışlardır ve uygulama sonuçları mekanik konularına ilişkin son test puanların da ATBÖ grubunun diğer gruba göre daha başarılı olduğunu göstermiştir. Gürsoy ve Taşdere (2012) Argümantasyon odaklı öğretim yönteminin ilköğretim 5. Sınıf öğrencilerinin dünya güneş ve ay konusundaki başarılarına etkisini araştırmışlardır ve deney grubu lehine anlamlı bir farklılığa ulaşmışlardır. Balcı ve Yenice (2016) öğrencilerin ATBÖ yaklaşımının hücre bölünmesi ve kalıtım konusundaki akademik başarılarını araştırmışlar ve deney grubu lehine anlamlı bir farklılık gözlemlemişlerdir. Benzer olarak Akkuş ve Kurt (2012) ATBÖ yaklaşımının kullanıldığı deney grubundaki öğrencilerin kavramsal sorularda daha başarılı olduğunu bulmuşlardır. Hand, Wallace ve Yang(2004) 7.sınıf öğrencileriyle yaptıkları çalışmada ATBÖ yaklaşımının geleneksel yaklaşıma göre kavramsal anlamaları geliştirmede daha etkili olduğunu ifade etmişlerdir. Benzer sonuçları Hand, Prain ve Wallace 10.sınıf öğrencilerinden, Greenbowe ve Hand(2005) ve Demirci (2008) üniversite öğrencilerinden elde etmiştir.

Öğrencilerin tartışma sürecinde ve sonunda yazdıkları MMY şablonundan elde edilen bulgulara göre; raporların toplam puanları ile fonksiyonlar başarı testinin son test toplam puanları arasında pozitif, orta düzeyde ve anlamlı bir ilişki tespit edilmiştir $(r=.614, p<.05)$. Yazma ve matematiksel problem çözme arasındaki ilişkiyi keşfetmek için yapılan çalışmalar, yazmanın, öğrencilere problem çözme davranışlarını organize etme ve onların bilgi şemalarını geliştirme konusunda yardımcı olduğunu göstermiştir (Steele, 2005). Aynı şekilde Pugalee (2004), öğrencilerin matematiksel yazmalarından üst-bilişsel davranış kanıtları sağlamıştır. Öğrenciler yazma stratejilerini ne kadar çok kullanırlarsa ve yazdıklarını gözden geçirirlerse o kadar dersten faydalanırlar (Kief, Rijlaarsdam and Bergh, 2006).Türkiye' de yazma üzerine yapılan çalışmalar incelendiğinde daha çok fen bilimleri öğretimi ile ilgili olduğu görülür (Akar, 2007; Günel, Atila ve Büyükkasap, 2009). Memiş (2011)'in yaptığı çalışmada ATBÖ raporları ile elektrik son test puanları arasında pozitif, orta düzeyde ve anlamlı bir ilişki tespit etmiştir. Memiş(2011)'in yaptığı araştırma sonuçları bu araştırmanın bulgularını destekler niteliktedir. Benzer şekilde Yeşildağ-Hasançebi ve Günel (2013) ATBÖ yaklaşımının ilköğretim seviyesinde maddenin yapısı ve özellikleri ünitesinde kullanılmasının öğrencilerin akademik başarısına katkı sağladığını ve öğrencilerin süreç içerisinde yazdıkları ATBÖ 
raporlarından aldıkları puanları ile son test puanları arasında olumlu bir ilişki olduğu gözlemlemişlerdir.

\section{Öneriler}

Araştırma sonuçlarına göre aşağıda bazı önerilere yer verilmiştir:

1. Çalışmada ATBÖ yaklaşımının "Fonksiyonlar" konusundaki öğrencilerin başarılarını artırmada etkili olduğu dikkate alınırsa, bu yaklaşım farklı sınıf ve konu düzeylerinde uygulanmalı ve etkililiği araştırılmalıdır.

2. ATBÖ yaklaşımının matematiğe karşı tutum gibi farklı değişkenler üzerine etkisi incelenebilir.

3. Öğretmenlerin ATBÖ yaklaşım sürecini öğrenmeleri, etkili tartışma yönetebilmeleri için bu yaklaşımın öğretmenlere hizmet içi kurslarda uygulamalı olarak anlatılmalı ve öğretmenlerin bu süreci sınıf içi uygulamalarına yansıtarak öğrencilerini bilimsel tartışmaya teşvik etmelidir.

\section{Makalenin Bilimdeki Konumu (Yeri)}

Matematik ve Fen Bilimleri Eğitimi/Matematik Eğitimi Anabilim Dalı

\section{Makalenin Bilimdeki Özgünlüğü}

$\mathrm{Bu}$ araştırma, daha çok fen alanında yaygın olarak kullanılan ATBÖ yaklaşımının matematik alanında uygulanabilmesini gösterebilme açısından önem arz etmektedir. Ayrıca ATBÖ yaklaşımının öğrencilerin fonksiyonlar konusundaki matematik başarılarına katkı sağladığını göstermek açısından da önem taşımaktadır.

\section{Kaynaklar}

Akar, M. S. (2007). Laboratuar dersinde yazma metinleri oluşturmanın ve analoji kullanmanın akademik başarlya etkisi. Yayınlanmamış Yüksek Lisans tezi. Atatürk Üniversitesi, Erzurum.

Akkuş, R. (2007). Investigating the changes in teachers'pedagogical practices through the use of mathematics reasoning heuristic approach. Unpublished PHD Dissertation, Iowa State University, Ames.

Akkuş, R. \& Kurt, İ. (2012, Haziran). Argümantasyon tabanlı tilim öğrenme yaklaşımının öğrenci akademik başarısına ve kritik düşünme becerisine etkisi, 10. Ulusal Fen Bilimleri ve Matematik Ĕ̆itimi Kongresi (UFBMEK), Niğde Üniversitesi,Niğde. 
Akkuş, R., Gunel, M., and Hand, B. (2007). Comparing an inquiry-based approach known as the science writing heuristic to traditional science teaching practices: Are there differences?. International Journal of Science Education, 1, 1-21.

Aldağ, H. (2006). Toulmin tartışma modeli. Çanakkale Üniversitesi Sosyal bilimler Enstitüsü Dergisi, 6(1), 13-34.

Balci, C. \& Yenice, N. (2016). Effects of the scientific argumentation based learning process on teaching the unit of cell division and inheritance to eighth grade students. Journal of Education in Science, Environment and Health (JESEH), 2(1), 67-84

Carpenter, T., Fennema, E., and Franke, M. (1996). Cognitively guided instruction: A knowledge base for primary mathematics instruction. The Elementary School Journal, 97(1), 3-20.

Ceylan, Ç. (2010). Fen laboratuar faaliyetlerinde argümantasyon tabanlı bilim öğrenme - atbö yaklaşımının kullanımı. Yayımlanmamış Yüksek Lisans Tezi. Gazi Üniversitesi Eğitim Bilimleri Enstitüsü, Ankara.

Dalkıran, G., Kesercioğlu, T., ve Boyacı, S. (2005, Eylül). Kavram haritaları ve kavramsal değişim metinlerinin öğrencilerin fen bilgisi dersine olan tutumlarına etkisi ve öğrenci görüşleri. Ulusal Eğitim Bilimleri Kongresi, Pamukkale Üniversitesi Eğitim Fakültesi, Denizli.

Demirci, N. (2008). Toulmin'in bilimsel tartışma modeli odakl eğitimin kimya öğretmen adaylarının temel kimya konularını anlama ve tartışma seviyeleri üzerine etkisi. Yüksek Lisans Tezi. Gazi Üniversitesi Eğitim Bilimleri Enstitüsü, Ankara.

Driver, R., Newton, P., and Osborne, J. (2000). Establishing the norms of scientific argumentation in classrooms. Science Education, 84(3), 287-312.

Druker, S. L., Chen, C., and Kelly, G. J. (1996). Introducing content to the toulmin model of argumentation via error analysis. Paper Presented At NARST Meeting II, Chicago.

Erduran, S., Ardaç, D., and Güzel, B.Y. (2006). Learning to teach argumentation: Case studies of pre-service secondary science teachers. Eurasia Journal of Mathematics, Science and Technology Education, 2(2), 1- 13. 
Erkol, M., Kışoğlu, M. \& Büyükkasap E. (2010). The effect of implementation of science writing heuristic on students' achievement and attitudes toward laboratory in introductory physics laboratory. Procedia Social and Behavioral Science 2, 2310-2314.

Günel, M. ve Tanrıverdi, K. (2012, Haziran). Boylamsal araştırma projesi: Hizmetiçi eğitim ve sınıf içi uygulamalarının, öğretmen pedagojisine, öğrenci akademik başarısına, düşünme becerilerine etkisinin araştırılması, 10. Ulusal Fen Bilimleri ve Matematik Eğitimi Kongresi (UFBMEK), Niğde Üniversitesi, Niğde.

Günel, M., Atila, M. E., ve Büyükkasap, E. (2009). Farklı betimleme modlarının öğrenme amaçlı yazma aktivitelerinde kullanımlarının 6. sınıf yaşamımızdaki elektrik ünitesinin öğrenimine etkisi. Illköğretim Online, 8(1), 183-198.

Günel, M., Uzoğlu, M., ve Büyükkasap, E. (2009a). Öğrenme amaçlı yazma aktivitelerinin kullanımının ilköğretim seviyesinde kuvvet konusunu öğrenmeye etkisi. Gazi Eğitim Fakültesi Dergisi, 29(1), 379-399.

Günel, M., Kabataş-Memiş, E., Yeşildağ, F., Biber, B, Okçu, B. \& Şahin, A. (2010). Argümantasyon Tabanlı Bilim Öğrenme (ATBÖ) yaklaşımının üniversite seviyesinde fizik laboratuarlarında kullanımın akademik başarıya etkisi. IX. Ulusal Fen ve Matematik Eğitimi Kongresi, 23-25 Eylül, İzmir.

Greenbowe, T., \& Hand, B. (2005). Introduction to the Science Writing Heuristic. In N. J. Pienta, M. Cooper, \& T. Greenbowe (Eds.), Chemist guide to effective teaching. Englewood Cliffs, NJ: Prentice Hall.

Hand, B. and Keys, C. (1999). Inquiry invertigation: A new approach to laboratory reports. The Science Teacher, 66 (4), 27-29.

Hand, B. Wallace, C. and Yang, E. (2004). Using the science writing heuristic to enhance learning outcomes from laboratory activities in seventh grade science: Quantitative and qualitative aspects. International Journal of Science Eduation, 26, 131-149.

Hand, B., Prain, V., \& Wallace, C. (2002). Influences of writing tasks on students' answers to recall and higher-level test questions. Research in Science Education, 32, 19-34.

Hohenshell, L.(2004). Enhancing science literacy though 1mplementation of writing- to learn strategies: Exploratory studies in high school biology. Doctoral Dissertation. Iowa State University, USA.

Hohenshell, L. and Hand, B. (2006). Writing-to-learn strategies in secondary school cell biology: A mixed method study. International Journal of Science Education, 28, 261. 
Jonassen, D. H., Peck K. L. and Wilson, B. G. (1999). Learning With Technology: A. Constructivisit Perspective. New Jersey, Prentice Hall.

Karaçay, T. (18 Kasım 2000). Matematik öğretimi. Matematik Yılı Matematik Öğretmenleri Semineri Tansel okulları, Sakarya. www.baskent.edu.tr/ tkaracay/ etudio/agora/math/sakarya.html 10.08.2014 tarihinde erişilmiştir.

Karasar, N. (2007). Bilimsel araştırma yöntemi. Ankara: Nobel Yayın Dağıtımı.

Kaya, O. N. (2005). Tartışma teorisine dayalı öğretim yaklaşımının öğrencilerin maddenin tanecikli yapısındaki başarılarına ve bilimin doğası hakkındaki kavramalarına etkisi. Yayımlanmamış Doktora Tezi. Gazi Üniversitesi Eğitim Bilimleri Enstitüsü, Ankara.

Keys, C. W., Hand, B., Prain, V. and Collins, S. (1999). Using the science writing heuristic as a tool learning from laboratory investigations in secondary science. Journal of Research in Science Teaching, 36(10), 1065-1084.

Kieft, M., Rijlaarsdam, G. \& Bergh, H. (2006). Writing as a learning tool: testing the role of students' writing strategies. European Journal of Psychology of Education, 21 (1), 1734.

Memiş, E.K. (2011). Argümantasyon tabanlı bilim öğrenme yaklaşımının ve öz değerlendirmenin ilköğretim ögrrencilerinin fen ve teknoloji dersi başarısına ve başarının kalıcılı̆̆ına etkisi. Doktora Tezi. Atatürk Üniversitesi Eğitim Bilimleri Enstitüsü, Erzurum.

Niaz, M., Aguilera, D. Maza, A. and Liendo, G. (2002). Arguments, contradictions, resistances, and conceple change in students understanding of atomic structure. Science Education, 86, 505-525.

Osborne, J. (2005). The role of argument in science education. Research and the Quality of Science Education,7, 367-380.

Pugalee, D. K. (2004). A comparison of verbal and written descriptions of students' problem solving processes. Educational Studies in Mathematics, 55(1-3), 27-47.

Rudd, J.A., Greenbowe, T.J., Hand, B. and Legg, M.L. (2001). Using the science writing Heuristic to move toward an inquiry-based laboratory curriculum: An example from physical equilibrium. Journal of Chemical education, 78, 1680-1686.

Sampson, V. and Clark, D. B. (2008). Assessing dialogic argumentation in online environments to relate structure, grounds, and conceptual quality. Journal of Research in Science Teaching, 45(3), 293-321. 
Steele, D. (2005). Using writing to access students' schemata knowledge for algebraic thinking. School Science and Mathematics, 105(3), 142-154.

Uluçınar Sağır, Ş. (2008). Fen bilgisi dersinde bilimsel tartışma odaklı öğretimin etkinliliğinin incelenmesi. Yayımlanmış Doktora Tezi. Gazi Üniversitesi Eğitim Bilimleri Enstitüsü, Ankara.

Yahşi, D. (2006). Farklı laboratuar yaklaşımlarının ilköğretim 8. sınıf öğrencilerinin asit-baz konularındaki kavramlar anlamalarına ve kavram yanılgılarının giderilmesine etkisi. Yayınlanmış Yüksek Lisans Tezi. Abant İzzet Baysal Üniversitesi Sosyal Bilimler Enstitüsü, Bolu.

Yeşiloğlu, S. N. (2007). Gazlar konusunun lise öğrencilerine bilimsel tartışma (argümantasyon) odaklı yöntem ile ögretimi. Yüksek Lisans Tezi. Gazi Üniversitesi Eğitim Bilimleri Enstitüsü, Ankara.

Yeşildağ-Hasançebi, F. ve Günel, M.(2013). Argümantasyon tabanlı bilim öğrenme yaklaşımının dezavantajlı öğrencilerin fen bilgisi başarılarına etkisi. İlkögrretim Online, 12(4), 1056-1073. http: //ilkogretim-online.org.tr

\section{Summary}

\section{Problem Statement}

The necessity of good mathematics teaching in schools is seen as an important goal at every stage of education. There is widespread belief that the achievement of students in mathematics in every part of society plays a more important and decisive role than the achievement they have shown in other lessons. For this reason, it can be assumed that why mathematics teaching is necessary is well known by everyone (Karaçay, 2000). The training of qualified individuals to meet the needs of society is only possible with the reveal and develop creative thinking skills in individuals.

Nowadays, new knowledge learned from individuals is expected to be structured with existing knowledge and skills. For this reason, it is important for the students to identify their prior knowledge before constructing the knowledge (Yahşi, 2006). This is because it is likely that the individuals who are trained in a learning environment where students are directly informed by the teacher without considering the information and their prior knowledge, and who are also assessing the students with stereotypical examinations (Dalkıran, Kesercioğlu and Boyac1, 2005). When considered from this point of view, different learning and teaching methods should help students to learn on their own (Günel, Uzoglu and Büyükkasap, 2009a). 
In the scientific debate, the students' research and inquiry ability improves because they work like a scientist (collecting data, providing justification, considering alternative interpretations, reaching to the conclusion with reasoning) while structuring their arguments. (Driver, Newton ve Osborne, 2000). A number of studies have been carried out on the scientific debate to enhance research skills in students (Druker, Chen and Kelly, 1996; Yerrick, 2000). These researches; demonstrates that the scientific debate positively changes students' ability to understand causal relationships, to create testable hypotheses, to design experiments, to solve real-life problems, and to have scientific research skills. In addition, since students do not work in groups in scientific discussion, it is aimed that students will have social interaction and cooperation by means of these group studies.

Practices such as the refutation of opposing ideas, the racing of hypotheses, and applications such as the provision of justifications are influential on the conceptual change. Scientific debates about conceptual change are also closely related to the discovery of student ideas and the refutation of false concepts (Uluçınar, 2008). In addition, during the scientific debate, the questioning of alternative ideas that students have and the fact that they are aware of the opposite reasons and scientific ideas in this process are accelerating the process of conceptual change Niaz, Alguilera, Maza and Liendo, 2002). Osborne (2005) emphasized that students' proving their beliefs through reasoning, guessing, evaluating the proofs and thinking over counter-arguments contribute to conceptual learning. Instead of using traditional methods, methods that will increase the creativity of students should be tried and developed.

In argumentation-based teaching, students exhibit their mental schema and they question not only their own views but also those of other students. Moreover, using reason and proof in order to support their claims, they put forward their higher-order reasoning and oral expression skills when necessary by invalidating counter-arguments with their rebuttals. From this point of view, many aspects stand out from the traditional approach (Uluçınar, 2008). From this point of view, many superior aspects stand out compared to traditional approach (Uluçınar, 2008). In constructivism, there is a need for individuals who produce their own technology, who are self-conscious, creative, researching, questioning, knowing what, where and why (Jonassen, Peck ve Wilson, 1999). In this approach the student is in the active position and the teacher mostly plans student-centered activities.

ABSL approach is an approach that is based on constructivist approach and is combined of constructivist learning models, the role of preliminary knowledge, reader involvement, causality associations, cognitive learning, and problem solving (Keys, Hand, Prain ve Collins, 
1999). This approach, which is more commonly used in the field of science and is also used in the field of mathematics, is important in terms of reviewing its impact on creativity. ABSL approach is also important since it is a discussion-based approach, in terms of the training and development of creative individuals that society needs who are not memorizing but constantly searching, inquiring, and advancing their ideas. In this study, it is envisaged that the practicing of ABSL approach in mathematics course will enable students to experience an exemplary learning environment in which they can realize their own creativity besides learning by learning without memorizing mathematical concepts. In this study, it is envisaged that the application of ABSL approach in mathematics course will enable students to experience an exemplary learning environment in which they can realize their own creativity besides learning by learning without memorizing mathematical concepts. In parallel with this approach, the general purpose of our research is to examine the impact of the argument-based science learning approach on the achievement of 9th grade students on functions and their creative thinking skills.

\section{Method(s)}

Quantitative method was used in the study. The study consisted of a single group pretestposttest weak experimental design. Karasar (2007) stated that a well-selected group variable was applied in the single group pre-test post-test model and stated that both pre-experiment (pre-test) and post-experiment (post-test) measures were applied. Research Bayburt Science High School was conducted with a total of 22 students, 11 girls and 11 boys in the 9th grade in the fall semester of 2012-2013 academic year. If it is considered that they all have received similar training in primary education and they are placed in the science high school with a certain base score from SBS (Level Determination Test), it can be said that all the students are very homogeneous. The objective sampling method, which is one of the unselected sampling approaches, has been used in the selection of the students. The initial state of the test, developed for the study, consists of 20 open ended questions. On the topic of the functions, a question pool was created by bringing together the questions from OSS-LYS-YGS examination in the past years. To determine which of the questions will be used, educational attainments related with the topics and the aim of the study was taken as the objective criteria and the statement table was prepared. The questions determined according to these criteria were not exactly used, multiple choice questions were turned into open ended questions. 20 questions were determined according to the generated statement table. The pilot study of the test was applied to a group of 50 students who were studying in the 10th grade and the total score obtained from each student's test was calculated. The calculated scores were ranked from small to large, and then 
the students were divided into 3 groups, the upper group consisted of 15 students, the middle group included 20 students and the lower group had 15 students. The discriminatory and difficulty indices for the test items were calculated according to these groups. Expert opinion has been consulted to ensure the validity of the test. 3 mathematics education specialists and 2 mathematics teachers who were working in high school were investigated and their validity was tried to be obtained by taking their opinions.

After the item analysis, the final version of the function achievement test was created to include 15 open-ended questions by removing some questions $(2,6,13,15,19)$. Reliability analysis was performed for the data obtained from the pilot application and the Cronbach alpha value was found to be .709. As a result of the pilot study, it was decided to apply the test within one hour. After the answer key is set for the Function Achievement Test, the correct answer for each question is given a value of 4 , and the wrong answer is given a value of 0 . In the evaluation of the open-ended questions, the holistic evaluation key was used for the problem solving given in the mathematics curriculum prepared by the Ministry of National Education. The SPSS 18.0 package program was used in the analysis of the data obtained from the pre-test-post test for the Functional Achievement Test. The skewness and kurtosis values for the normality condition, which is the condition of the parametric, were examined between -1 and +1 and the paired sample t-test was performed. The Skewness and kurtosis values of the Functional Achievement Test, which are separated into categories, are between -1 and +1 and the paired sample t-test is used.

\section{Findings and Discussions}

The data obtained from the application of the achievement test as the pre-test and posttest in the practice group were subjected to statistical analysis in order to reveal the possible differences between the pre-test and the post-test. The results of the statistical analysis revealed that the average score of the students' achievement test was 7.23 before applying the ABSL approach, and the average score of the same test after the application increased to 42.77. The paired sample, which is decided to be used to determine whether there is a statistically significant difference between the pre-test and the post-test, indicates that the calculated skewness and kurtosis values are between -1 and +1 , and that the data normally distribute before determining whether the necessary assumptions are met. The results of the analysis performed after determining that the necessary assumptions were satisfied revealed a statistically significant difference in the significance level of .05 between the achievement pre- 
test and post-test $(\mathrm{p}=.00<.05)$. In other words, it can be said that the ABSL approach used in teaching mathematics is a successful method for increasing the students' achievement in terms of functions.

Function Achievement Test consisting of 15 open ended questions was divided into 4 categories by taking expert opinions. The categories were formed as 4 questions in A category, 3 in B category, 4 in C category and 4 in D category for 15 open-ended questions. Category A is a category that contains operational questions at a more basic level. Category B contains a bit more difficult questions than the questions in category A regarding understanding basic information. Category $\mathrm{C}$ is a category that contains graphic questions and category $\mathrm{D}$ is a category that contains mostly reasoning type questions. In the four categories of Function Succrss Tests, averages of the scores of each category were calculated and a paired sample ttest was conducted to determine whether there was a significant difference between the scores of the students in the pre-test and the post-test of each category. According to Table 2, it is seen that the students who participated in the survey had a final test score average of 13.55 , the average of the scores obtained from the pre-test of the sub-dimension is 4.00 . According to the results of the paired sample t-test to determine whether there is a significant difference between the averages of the students in this category, it was found that there was a statistically significant difference in favor of the post- test $(\mathrm{p}=.00<.05)$. When the results of the subdimension B are examined, it is seen that the average of the pre-test scores of the students is 0.91 and the final test score average is 8.09. As a result of the analysis to determine the statistical difference, it was found that the significant difference detected was in favor of the post test $(\mathrm{p}=.00<.05)$. In the other sub-dimension $\mathrm{C}$ dimension, mean of the pre-test scores of the students was determined as 0.72 and the final test scores were calculated as 10.81 . Likewise, statistical analysis results to determine whether development is statistically significant show that post-test results are in favor of the final test $(\mathrm{p}=.00<.05)$.

Finally, when we look at the analyzes for the sub-dimension D, it is seen that the average score of the students in this sub-dimension pre-test is 0.18 , whereas the average score of the final test is 11.77 . The paired sampled t-test results also revealed a statistically significant difference between the pre-test and the post-test is in favor of the final test ( $p=.00<.05$ ). The results of the One-way ANOVA used to determine which of the four different categories of achievement was more effective in the achievement test $(\mathrm{p}>.05)$ indicated that there was no statistically significant difference between the two groups in terms of achievement in subcategories. In other words, the results obtained can be interpreted as the fact that the applied 
argument-based training method has the same level of influence on the achievement of each subcategory.

\section{Conclusions and Recommendations}

This research is also very important in that it shows that the debate is not just a practice among adults, and that secondary school students in the first stage can also make meaningful debates. It is also important to show that the ABSL approach contributes to students' mathematical achievements in terms of functions. Based on the ABSL approach, it was determined that there was a significant difference in favor of the post-test when the results of the achievement tests applied to the students before and after the functions were evaluated $(p=.00<.05)$. When the findings were examined, the mean pre-test score of the students was 7.23 while the post-test score average was 42.77 . In other words, it can be said that the ABSL approach used in teaching mathematics is a successful method for increasing the students' achievement in terms of functions. According to the findings obtained from the MMY template written by the students during the discussion process and at the end; a positive, moderate and significant relationship was found between the total scores of the reports and the final test total scores of the functions achievement test $(\mathrm{r}=.614, \mathrm{p}<.05)$.

According to the results of the research some suggestions are given below:

1. If it is taken into account that the ABSL approach to study is effective in increasing the achievement of the students on the "Functions" topic, this approach should be applied at different class and subject levels and its effectiveness should be investigated.

2. The research is conducted in a limited time period and the effects of the ABSL approach on different variables such as attitudes towards mathematics can be examined by conducting longer researches.

Keywords: Achievement, argumentation, function, mathematics, student 